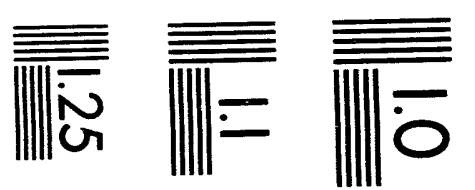

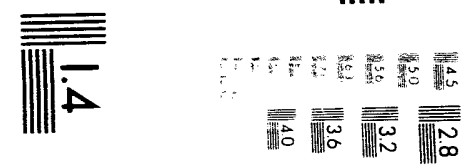

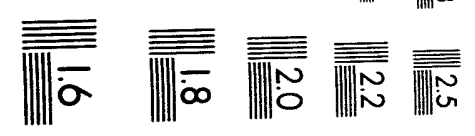



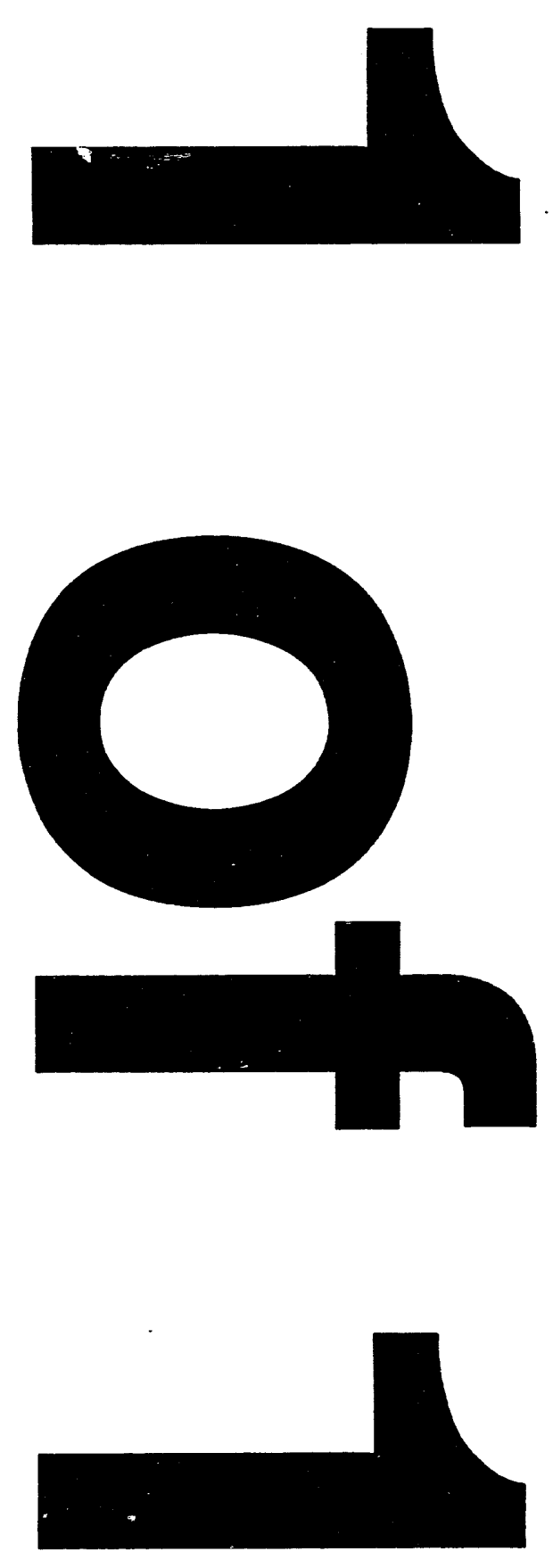


\title{
Test Plan for Prototype Dielectric Permittivity Sensor
}

\author{
M. C. Pfeifer
}

Published July 1993

Idaho National Engineering Laboratory

EG\&G Idaho, Inc.

Idaho Falls, Idaho 83415

Prepared for the

U.S. Department of Energy

Office of Environmental Restoration and Waste Management

Under DOE Idaho Operations Office

Contract DE-AC07-76ID01570

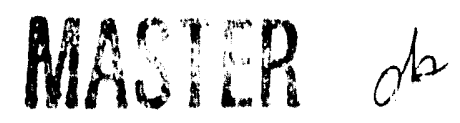

WIORIBUTION OF THIS UDCLIMENT IS UNLIMITED 


\section{Test Plan for Prototype Dielectric Permittivity Sensor}

EGG-WTD-10812

Prepared by

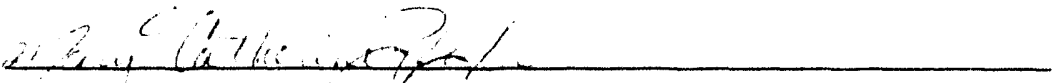

M. C. Pleifer, Principal Inyéstigator

Applied Geosciences Únit

Reviewed by

$$
\text { FA }{ }^{1} \mathrm{~s} / \mathrm{low}-
$$

R. A. Callow, Project Manager

Buried Waste Integrated Demonstration

Approved by

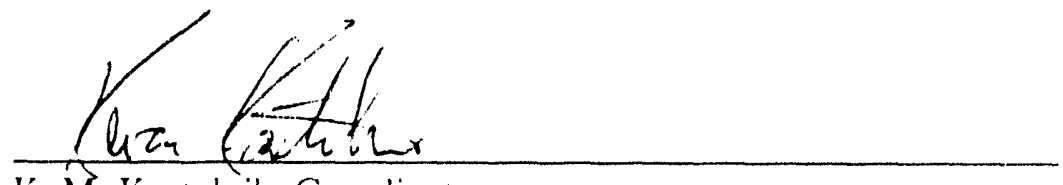

K. M. Kostelnik, Coordinator

Buried Waste Integrated Demonstration

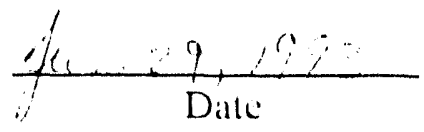

$7 / 1 / 93$

Date

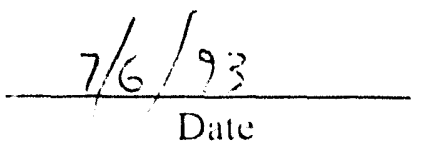




\begin{abstract}
The digface characterization project funded by the Buried Waste Integrated Demonstration (BWID) is designed to test a new method of monitoring hazardous conditions during the remediation at waste sites. Often on a large scale, the exact cause of each anomaly is dilficult to determine and ambiguities remain in the characterization of a site. The digface characterization concept is designed to alleviate some of this uncertainty by creating systems that monitor small volumes of soil and detect anomalous areas during remediation before they are encountered. The goal of the digface characterization demonstration is 10 detect changes in the physical properties from one volume to another and relate these changes in physical properties 10 changes in the level of eontamination. Dielectric permittivity mapping is a method that might prove useful in digface characterization.
\end{abstract}

In this project, the role of a dielectric permittivity monitoring device is under investigation. This project addresses two issues: what are the optimal means of mapping dielectric permittivity contrasts and what types of targets can be detected using dielectric permittivity mapping. 


\section{CONTENTS}

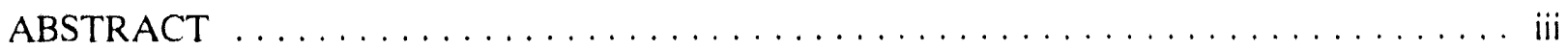

1. INTRODUCTION $\ldots \ldots \ldots \ldots \ldots \ldots \ldots \ldots \ldots \ldots \ldots \ldots \ldots \ldots \ldots \ldots$

1.1 Background $\ldots \ldots \ldots \ldots \ldots \ldots \ldots \ldots \ldots \ldots \ldots \ldots \ldots \ldots \ldots \ldots \ldots \ldots \ldots \ldots \ldots \ldots$

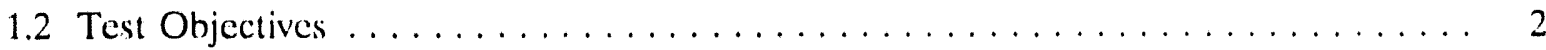

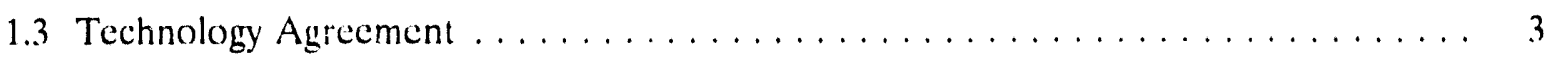

2. ORGANIZATION AND RESPONSIBILITIES $\ldots \ldots \ldots \ldots \ldots \ldots \ldots \ldots \ldots \ldots$

3. DESCRIPTION OF TEST $\ldots \ldots \ldots \ldots \ldots \ldots \ldots \ldots \ldots \ldots \ldots \ldots \ldots \ldots \ldots \ldots$

3.1 Laboratory Equipment $\ldots \ldots \ldots \ldots \ldots \ldots \ldots \ldots \ldots \ldots \ldots \ldots \ldots \ldots$

3.2 Proposed Physical Models $\ldots \ldots \ldots \ldots \ldots \ldots \ldots \ldots \ldots \ldots \ldots \ldots \ldots \ldots \ldots$

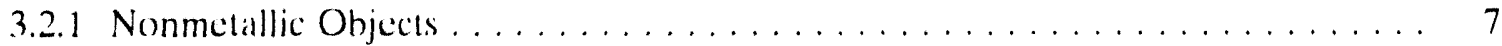

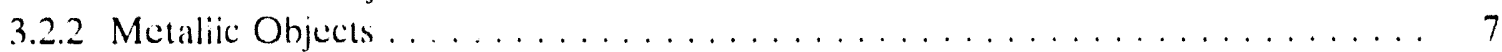

3.2 .3 Liquid Targer $\ldots \ldots \ldots \ldots \ldots \ldots \ldots \ldots \ldots \ldots \ldots \ldots \ldots$

3.3 Laboratory Measurements $\ldots \ldots \ldots \ldots \ldots \ldots \ldots \ldots \ldots \ldots \ldots \ldots \ldots \ldots$

3.3 .1 Data Collection $\ldots \ldots \ldots \ldots \ldots \ldots \ldots \ldots \ldots \ldots \ldots \ldots \ldots$

4. SEQUENCE OF ACTIVITIES $\ldots \ldots \ldots \ldots \ldots \ldots \ldots \ldots \ldots \ldots \ldots$

5. SAMPLING AND DATA $\ldots \ldots \ldots \ldots \ldots \ldots \ldots \ldots \ldots \ldots \ldots \ldots \ldots \ldots \ldots$

6. DOCUMENT CONTROL $\ldots \ldots \ldots \ldots \ldots \ldots \ldots \ldots \ldots \ldots \ldots \ldots \ldots \ldots \ldots$

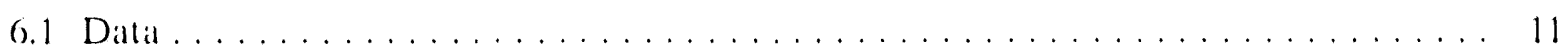

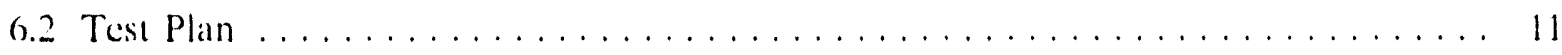

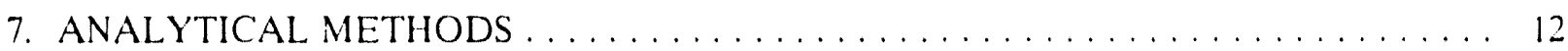

8. DATA REDUCTION, VALIDATION, AND VERIFICATION $\ldots \ldots \ldots \ldots \ldots \ldots$

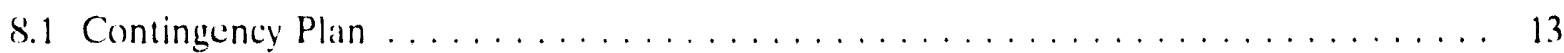

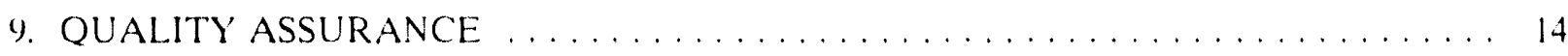

10. EQUIPMENT AND INSTRUMENTS $\ldots \ldots \ldots \ldots \ldots \ldots \ldots \ldots \ldots \ldots$ 
11. SUPPLIES. UTILITIES, AND FACILITIES $\ldots \ldots \ldots \ldots \ldots \ldots \ldots \ldots \ldots$

12. HEALTH AND SAFETY $\ldots \ldots \ldots \ldots \ldots \ldots \ldots \ldots \ldots \ldots \ldots \ldots \ldots$

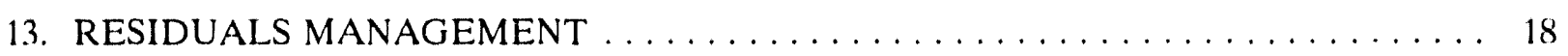

14. REFERENCES $\ldots \ldots \ldots \ldots \ldots \ldots \ldots \ldots \ldots \ldots \ldots \ldots \ldots \ldots \ldots$

Appendix A-Self-Assessment Surveillance Ruport and Walk-Through Checklist $\ldots \ldots \ldots \ldots \ldots \ldots \ldots \ldots \ldots \ldots \ldots \ldots \ldots \ldots \ldots$

\section{FIGURES}

1. Dielectric permittivity sensor project organization chart. $\ldots \ldots \ldots \ldots \ldots \ldots \ldots$

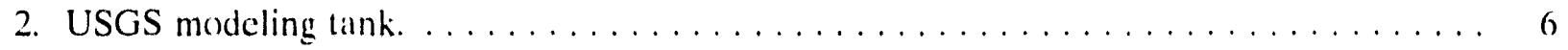

\section{TABLE}

1. Types of physical models $\ldots \ldots \ldots \ldots \ldots \ldots \ldots \ldots \ldots \ldots \ldots \ldots \ldots \ldots \ldots$ 


\section{Test Plan for Prototype Dielectric Permittivity Sensor}

\section{INTRODUCTION}

\subsection{Background}

Physical modeling to determine the optimal method for monitoring changes in dielectric permittivity is part of the larger diglace project being lunded by the Buried Waste Integrated Demonstration (BWID). ' The project is designed to lest a new method of monitoring hazardous conditions during remediation at waste sites. The variations in the physical properties at waste sites are complex; they can be caused by metallic objects, liquid and solid contaminants, or other manmade objects. Often on a large seale, the exact cause of each anomaly is indeterminate, and ambiguities remain in the characterization of a site. The diglace characterization approach is designed to alleviate some of this uncertainty by creating systems that monitor small volumes of soil and detect anomalous areas during remediation before they are encountered. Small volumes of investigation often minimize complicated signals from outside the volume of investigation. The goal is to detect changes in the physical properties from one volume $t 0$ another and relate these changes in physical properties to changes in the kevel of contamination.

The dielectric permittivity prototype testing will begin development on a dielectric permittivity mapping tool for the shallow subsurfice that will be used in a diglace characterization system. In clean uneontaminated soil, the dielectric permittivity of the volume of investigation is directly related (1) the water content of soil in that volume. An effective means of monitoring mosisture content of soils uses changes in dielectric permiltivity within the survey area. However, the presence of organic and inorganic malcrials, such as hydrocarbons and metallic oxides, also signilicantly alters the dielectric permittivity of soils in many instances.

To measure dielectric permittivity, high lrequency electromagnelic sensors are used. At high frequencies, the displacement currents appreciably contribute to the electromagnetic field aleng with conduction currents; the electromagnetic field associaled with a medium is dependent on both the conductivity and dielectric permiltivity of the medium. The most commenly used methods are radar methods with time domain reflectomelers (TDR). Radar uses freguencies between I MHz and $1 \mathrm{GHz}$ and are often severely allenuated by conductive soils. TDR systems use a probe system to measure the dielectric permiltivity between the probes. Another melhod al measuring the dielectric permittivity is to use high frequency electromagnetic sensors that operate in the range between $300 \mathrm{kHz}$ and $30 \mathrm{MHz}$. With this type of system. the conductivity can be delermined along with the dielectric permittivity. In all three of these systems, the conductivity alliects the response of the system. Thus, metallic objects can be delected using high frequency electromagnetic devices.

For this project, Iwo systems will be used, a TDR system and high frequency electromagnetic device developed by the United Stales Geolegical Survey (USGS), which oflers the ability lo vary the depth of investigation. The anticipalled benelits of using lwo systems ane three-fold. The first is to monitor changes in dielectric permillivity for small, limiled volumes of soil. The second is to investigate the potential of the high frequency system to not only simple a small volume but to also

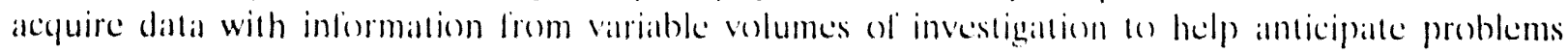
before the excavation system encounters them. The third is 10 use the information gatined from these 
tests to evaluate the performance of the devices not only to determine the applicability of dielectric permittivity mapping to the digface project, but after evaluation, to help design an optimal system for digface applications.

TDRs operate using the principle that electromagnetic waves propagate slower through mediums where the dielectric permittivity is high as opposed 10 mediums with a low dielectric permittivity. Thus, from the propagation time, a measure of the dielectric permittivity can be found. The conductivity of the medium affects the amplitude of the signal not the propagation time. The volumetric limitation of the TDR is 6 in. and cannot be varied. This gives the investigation a limited volume of investigation around the probe. While a very limited volume of investigation is a goal of the digface project, the TDR system has two drawbacks. The first is that it is an intrusive device. During remediation, contamination of the probes would occur. Second, the depth of the instrument is fixed and cannot be easily modified to investigate decper.

The high frequency electromagnetic sensor measures the quadrature and in-phase components of the total, vertical, and radial magnetic liekds. To account for the primary lield, the tilt angle and ellipticity parameters for the polarization ellipse are calculated from the quadrature and in-phase measurement. ${ }^{2}$ This is a coil-based system operated at variable frequencies, and the coil separations allow for variable depths of investigation. The present system needs to be modified with smaller coils so that the depth of investigation can be decreased. This modification will be eompleted before the initial lests. Using this device with the TDR system will give coverage of the entire region of the modeled diglace. From these meisurements, an optimal system will be designed.

\subsection{Test Objectives}

The current kesting is designed to provide intial informattion on the leasibility of using a dielectric permittivily sensor at the digface. As an initial demonstrattion of leasibility (or lack of leasibility), the testing uses simple model targets that are incended to represent real situations but are more amenable to initial demonstration and modeling. The kest objectives using these simple model largets are

1. Determine whether changes in diclectric permiltivity cian be meisured and related to physical changes in the model (i.e., larget conligurations).

2. Determine the optimum way to map dielectric permittivity contracts by using the target configurations to evaluate the effect of instrument parameters (e.g., freeguency) on ability (1) map) contrasts.

3. Evaluate the relative effectiveness of time domain rellectomedry and high frequency electromagnetics in mapping dielectric permiltivity contrasts. This evaluatlon is intended (1) result in a recommendation of a preferred system for lurther development.

To meet objective 1, several different conligurations will be kested. The dielectric permittivity sensor may be able of delect the lollowing classes of objects: solid objects, plume sludges, and contaminated soils. Within these broad calleguries, there are additional subeateguries. However, this initial testing will be locused on the main classes of tatgets by using the kesting targets shown in Table 1. 
Table 1. Types of physical models.

\begin{tabular}{|c|c|c|}
\hline Physical targets & $\begin{array}{l}\text { Models used in } \\
\text { laboratory tests }\end{array}$ & Quantity measured" \\
\hline $\begin{array}{l}\text { Plumes } \\
\text { Liquids } \\
\text { Sludges }\end{array}$ & Liquid and clay models & Relative dicisctric permiltivity \\
\hline $\begin{array}{l}\text { Solid objects } \\
\text { Metallic } \\
\text { Nonmetallic }\end{array}$ & Metallic and clay models & Relative dielectric permitlivity \\
\hline Contaminated soils & Clay and liquid models & Relative dielectric permiltivity \\
\hline
\end{tabular}

The targets will be placed in a sand matrix that servess as the host mallerial. Sill waler will be introduced into the sand as necessary to adjust solid conductivity into the range representative of Idaho National Engineering Laboratory (INEL) soils. (As described in more detail in Section 3, this will be done to malleh a key parameter allecting signal allemuation.)

The chosen physical models are simple models with simple solutions thatl can be casily analyzed and compared. A secondary purposse is 10 pertorm studies an beller understand the effects of contaminants on the dielectric permiltivity and determine if these effects are meisurable.

\subsection{Technology Agreement}

The echnology agreement with the BWID Program is as defined in the decumentation for work

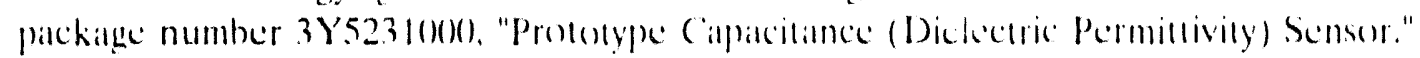




\section{ORGANIZATION AND RESPONSIBILITIES}

Key project personnel are shown in Figure 1. The principal investigator is $M$. C. Pleifer of the Applied Geosciences Unit at EG\&G Idaho, Inc. D. C. Stewart and V. F. Labson of the USGS Branch of Geophysies in Denver, Colorado, developed the prototype system being lested. Physical modeling will he performed in Denver at the USGS Branch of Geophysics. The modeling facility consists of a $15 \times 9 \times 5$-ft modeling tank with a data acquisition system. USGS participants will set up the laboratory equipment and with the EG\&G Idaho principal investigitor perform the laboratory modeling and interpret the data collected. The USGS participants and principal investigator are qualified to operate the equipment.

The principal investigator. Pfeifer, will he referred to as the cest leader in this report. USGS participant. Labson, is the designated lest leader when Pleifer is absent from the lest site.

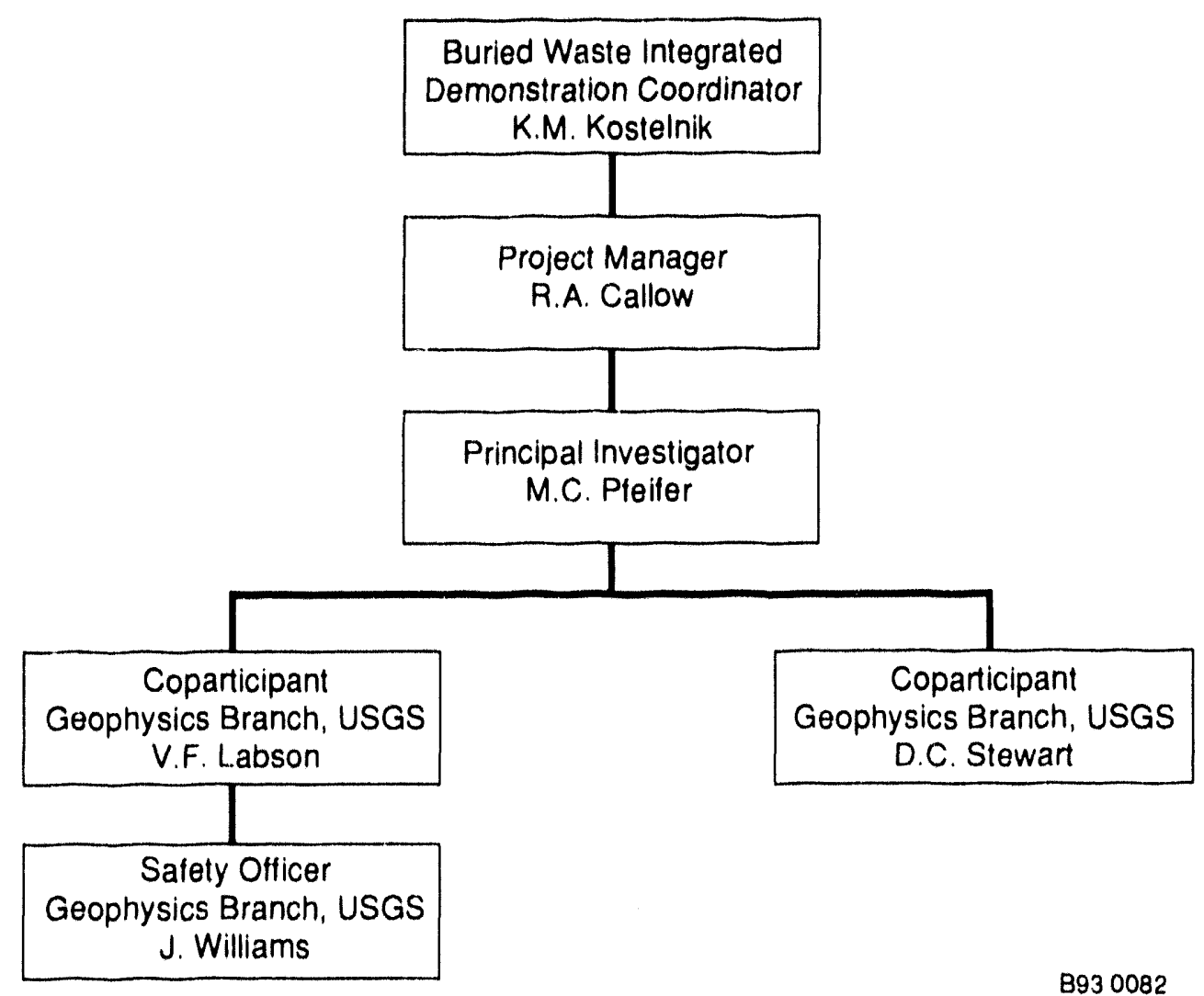

Figure 1. Dielectric permittivity sensor project organizallion chart. 


\section{DESCRIPTION OF TEST}

The purpose of this testing is to investigalle the role of a diclectric permittivity monitoring deviee and address three issues: first. can changes in diclectric permittivity be meisured and related to known physical changes within the model: secend. what is the optimal meins of mapping diclectric permittivity contrasts: and third, whal types of targets can be delected using dielectric permiltivity mapping. The less objective is o determine the effectiveness of monitoring for dielectric permitlivity changes at the diglate scale. The ests perlormed will be used to evalualle this eflectiveness and determine the best means of data collection and evaluation. This test is a preliminary test that is not designed to evaluate data collection rates or calse of data collection. The primary purpose is to demonstrate the utility of dielectric permittivity measurements at the diglace. At the completion of this test. recommendations on the development of a sensor for the diglate system will be made.

\subsection{Laboratory Equipment}

Physical modeling will be pertormed al the Denver. Coldrade, LSGS Branch of Geophysics. The modeling facility consists of a $15 \times 9$, 5 -1t modeling tank with a data acquisition system (sece Figure 2). The USGS sensor can be mounted on a gantry to alutomatically move the sensor to the measuring positions: however, initially the sensor will be placed manually: During the lests if it is found that the gantry increases efficiency of the modeling fictilites, it will be utilized at that time. The TDR probes will be placed manually beciase they must be placed in the medium.

The matrix used to contain the targets will be sand insleidl of soil. The use of sand minimizes heterogeneities in the host medium so thall response of the latgets can be betler quantified. Heteregencities that could arise becaluse of solit compaction from walking on the testhed are reduced by using sand. This approath is apprepriale for the initial leasibility demonstration. Future cesting. if warranted by initial results, will evaluate inlerlerences arising trom soil heteregenediles.

To approximalle soril conditions related to a key physical parameler that allects dielectric permittivity measurements, the electrical conductivity of the sand will be adjusted to approximate conductivities of representative INEL soil (approximalley so milliscimens per meler). As shown in Figure 2. a pump and leach pipe will be used to sitturale the sand with a dilute saline solution to adjust electrical conductivity. The pump recirculates a diluke saline solution until a sleady state is reached. Then the pump will be lurned afl and measurements tatien. The use of realistic conductivity in the host medium provides a realistie delermination of allenuation of the signal. Severe allenuattion could hamper the ellectiveness of the diclectric permitlivily lechniques: therefore. realistic values for host conductivities are necessary for the keasibility demonstration. The conductivity of the sand matrix will be measured at the beginning of the experiments using a Miller solitbox ${ }^{3}$ and recorded in the laboratory nocebout.

\subsection{Proposed Physical Models}

The physical models chosen fill into thece cillegories: metallic objects, solid dielectric

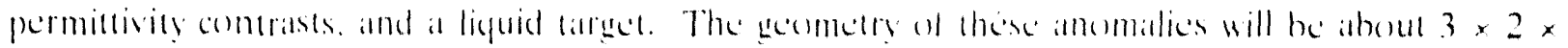

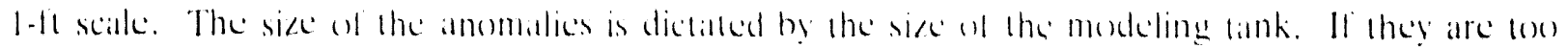
large, there will be interlerence with the meisurements from the sides of the lank. This is 

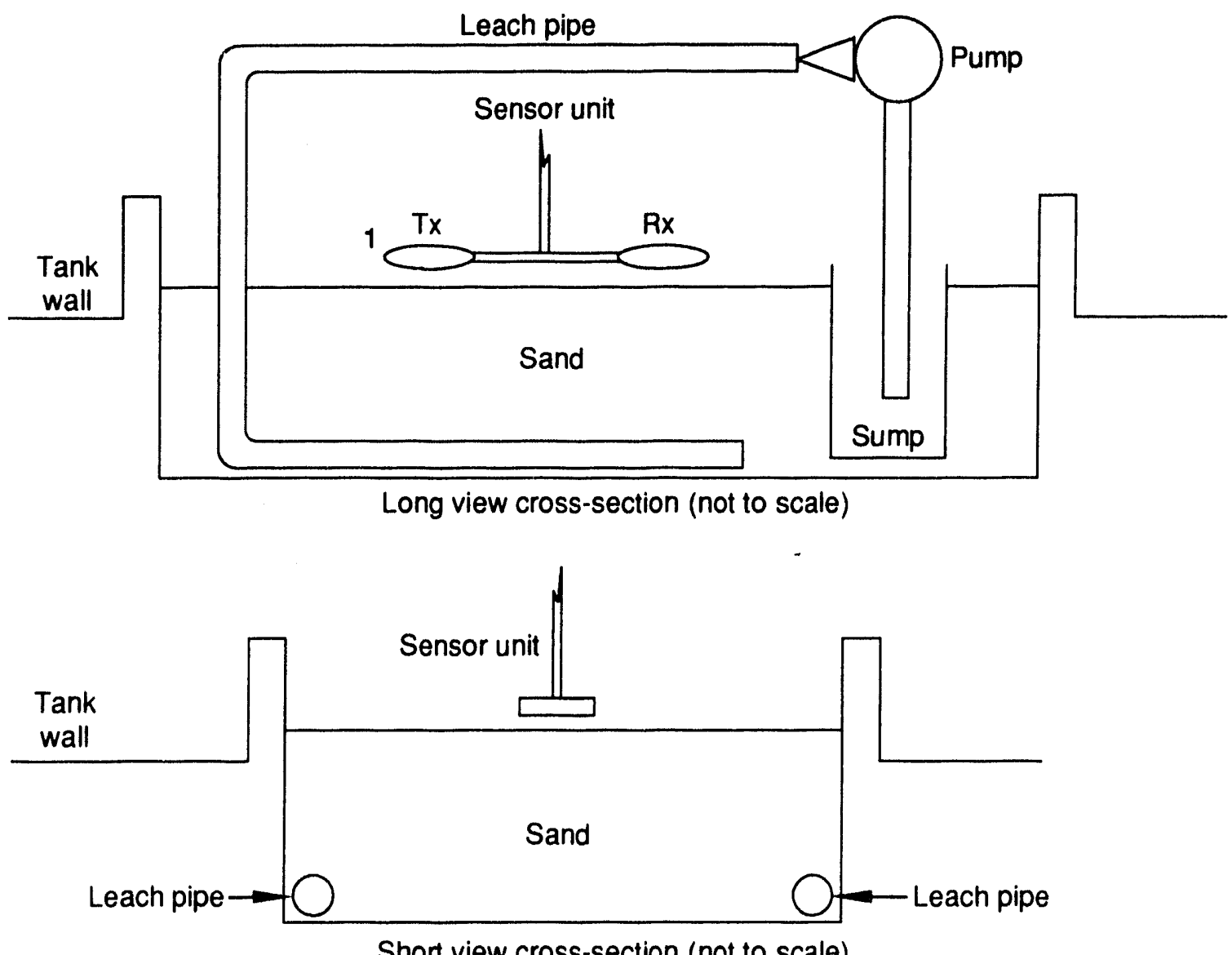

Figure 2. USGS modeling tank. 
appropriate for investigating the technology for the digface system. The bottom of the tank has a similar effect to the bottom of the INEL waste pits because they overlie crystalline basalt. Thus, in many aspects, the concrete bottom of the modeling tank is similar to the bottom of a waste pit. The sides of the tank are not similar to the sides of the INEL waste pits because they are not crystalline, and so the anomalies used need to be well away from the sides of the lank.

The test approach will be stepwise in that initial experiments will be conducted for a simple configuration of major importance in demonstrating feasibility of the technique. This conliguration is a clay target in soil that simulates the generic class of nonmetallic objects in soil. Assuming that initial results are positive, tests will be performed to simulate metallic and liquid targets in soil.

\subsubsection{Nonmetallic Objects}

Nonmetallic objects occurring at waste sites include not only items such as wood, plastic, and other solid objects but also contaminated soils and soils with sludges. The effects of these types of targets are unknown. Therefore, for a preliminary test, clay targets will be used. Clay has an advantage over other materials in that it can be used to simulate many different shaped objects. It is conductive, and if the host medium is conductive, the response measured will be due to the dielectric contrast between the host and target, and the conductivity response will be minimized. The use of clay is not intended to exactly mimic all of the properties of solid objects; it will, however, give an estimate of how such objects effect high frequency electromagnetic measurements.

One or more tests will be performed using the clay largets. An initial test will be conducted with a clay target (approximately $5 \mathrm{ft}^{3}$ ) placed approximately $1.5 \mathrm{ft}$ deep in the sand matrix. As described in Section 5, for each target configuration. measurements using the TDR will be performed by placing the TDR probes into the matrix. Probe locations will be delined by the test leader. Details about placement and data collection will be logged by the test leader (or designee) into the laboratory notebook.

The USGS high frequency electromagnetic sensor will be deployed above the target/host medium (see Figure 2). Medsurements will be made on a defined grid pallern lo be decermined by the test leader. All details of target configuration and datis collection will be logged into the laboratory notebook by the lest leader or designated kest participants. It is anticipated that approximately two diflerent target configurations will be used.

Additional tests may be conducted using targethost configurations as determined by the test leader based on evaluation of previous data. All lest target conligurations will be documented in a laboratory notebook using sketches and narrative descriptions as appropriate. Additional details of activity will be logged into the laboratory notebook.

\subsubsection{Metallic Objects}

A metallic object will be used to test its effect on the measurements. Metallic objects are most easily detected using magnetometers and conductivity mapping devices. However, metallic objects have an elfect on dielectric permitlivity deviess, and this test will help delermine the response. The metallic target object will be chosen by the est leader and documented in the laboratory notebook. 
Measurements of geometric shape will be recorded. Testing for various target/host configurations will proceed in a manner analogous to the testing defined above for nonmetallic objects.

\subsubsection{Liquid Target}

Leakage and transport of contaminants is a concern because the volume of contamination may not be apparent from monitoring solely for solid objects. Thus it is important 10 model such diffusive phenomena. A liquid target will be used to simulate the eflect of contaminants within the soils. A nonhazardous surrogate will be used in the place of a hazardous material. A lluid with a contrasting dielectric permittivity will be used to determine if a diffuse target can be detected.

\subsection{Laboratory Measurements}

In the laboratory tests, the models used will be explored in a fashion similar to the diglace concept of stripping layers from the area and then reinvestigating the area to detect changes in the dielectric permittivity as the target is approached. Using the TDR sensor and USGS high frequency system together has two purposes. The first is to have a comparison of the TDR data set with the USGS system's data set. The second is to investigate the high frequency electromagnetic sensor's ability to accurately distinguish anomalies at different depths. In the second casce the TDR will be used to correlate the near surlace TDR measurement with the deeper measurements from the high frequency electromagnetic sensor.

\subsubsection{Data Collection}

Data will be collected in a spatial arraly. The data collection will be perlormed in a fashion similar to the digface characterization system. An array will be laid out manually, and measurements will be taken at each station. Then, the upper portion of the model will be removed. The same horizontal positions will be used at this new vertical position for the next series of measurements. The horizontal station separation of this array will be modified als the tests progress to ensure the optimum eoverage of the model. The anticipated scale of the station separation is on the order of 15 to $40 \mathrm{~cm}$. The TDR are single point measurements at each station location, whereas the measurements using the USGS sensor system are more complex. These measurements are multifrequency meisurements that also use diflerent sensor separations to vary the depth of investigation. The depth of investigation is limited by the depth of the modeling tank. Multiple frequencies will be collected lor each coil separation al catch station. These data will be stored on compuler diskelles. 


\section{SEQUENCE OF ACTIVITIES}

The anticipated activities for this project are as follows.

1. Modeling facility at the USGS will be prepared for tike models used. The models used will be documented in the daily logbook as sketches with the position and type of target indicated on the sketch. The horizontal grid will be permanently placed in the modeling tank and its coordinates skctched in the logbook.

2. USGS sensor coils will be modified to collect closer spaced data.

3. Physical modeling will be performed. A horizontal grid will be laid out covering the internal portion of the modeling tank. The station positions will be recorded in the laboratory daily logbook. These stations will then be used to collect data from the TDR and USGS sensors. The data will be collected on a spatial array. The data will be collected over a horizontal grid that is reoceupied with dillerent sand overburdens to t' e target. This data will be recorded in the logbook daily and on eomputer diskettes.

For each target configuration, the stations will lirst be oceupied using the TDR system. The station location and measured value will be manually recorded in the logbook with verification. Verification will be dene by the operater of the TDR at the time of data collection by visually confirming that the number recorded into the loghoot coincides with the value recorded on the TDR. Initially, measurements al cach station will be made. If during the course of the investigation, the applicability of TDR measurements is found to be minimal. or the number of stations is lound to be redundant, the frequency of the measurements will be modified. Any change in the data collection will be noted in the loghook and discussed in the linal report. The TDR will be used as outlined in the Cambel Electronics operating manual. Data that are recorded manually will be stored on lloppy diskettes and verified to ensure data quality.

For each target configuration after the lirst survey using the TDR system, the USGS system will be used. This system is a two enil unit. Al eitch stittion, the coil separation will be varied to obtain data for different volumes. The anticipalled eoil separations used will be $.5, .75$, and $1.0 \mathrm{~m}$. Dillerent separations maly be used if the study linds that different separations would optimize the datta content. These changes will be documented in the logbook and linal report. The dalla from the USGS sensor will be collected using the procedures outlined References 2 and 3. Dallit will be collected and stored on a PC with notations in the kghosti as needed.

The TDR system will be manually moved from one station to the next. The USGS system will be moved either manually or with the help of a gantry system. This will be determined at the start of the survey. If it is found that the modeling is licilitaled hy the gantry, it will be used. If the gantry system dees not contribute to the ealse of datal collection, it will not be used. 
For the target conliguration after completion of first survey using the two devices, approximately $.1 \mathrm{~m}$ of sand will be removed from the model. The stations laid out in the initial grid will be reoccupied at this different vertical position.

Horizontal station positions will be permanently laid out so that they may be reoceupied each time, which minimizes errors incurred from positioning inaccuracies.

4. After data from both the TDR and USGS systems have been collected for a specilie target configuration (including soil removal sequence of activities), the model tank will be configured for the next test.

\section{SAMPLING AND DATA}

No soil sampling or analyses will be eonducted as part of these experiments. The TDR will be used to determine the dielectric permittivity of the specific sand and clay used in the experiments.

The data from these tests consist of electronic measurements from the TDR and USGS high frequency electromagnetic sensor for each measurement locillon of each test run. The USGS high frequency electromagnetic sensor data will be collected using the procedures oullined in References 2 and 4 . These data will be automatically stored on a PC with logbook notations as needed.

The TDR data will be manually recorded in the loghook by reading ofl the instrument. These data will be manually entered into a eomputer file for electronic storage in a BWID data base. 


\section{DOCUMENT CONTROL}

\subsection{Data}

The data collected during the lest will be stored on loppy disks and delivered to the BWID project manager for archiving. A copy will also be made for inclusion in the geophysics prototype dielectric permittivity sensor project life. The disks will be write protected. A daily leghook of the modeling done will be kept. In this book, any changes to the lest plan along with the daily operation of the tests will be documented.

A daily loghook will be maintained that documents the station positions, data collected with the TDR system, and daily activities. All entries into the logbouk will be made in ink and all pages numbered. Any changes in the test plan will also be documented in this logbook.

\subsection{Test Plan}

The est plan will be reviewed by the project manager. All changes will be approved by the test keader or the project manager. Any minor deviations or changes made to the test plan will be documented in the loghook aleng with the approval from the est leader. Major changes will require approval of the test leader and digface project manager. Major changes are those that allect the lest ohjective or compromise the quality of the datit. In the event that initial restals indicate that completion of all tests is not warranted. this will be documented by the kest kider with concurrence obtained from the project manager to discontinue cesting. 


\section{ANALYTICAL METHODS}

The data will be reduced to the relative dielectric permittivity. For validation and verification, the resulting relative dielectric permittivity will be compared to the known model to determine the accuracy of the measurements. 


\section{DATA REDUCTION, VALIDATION, AND VERIFICATION}

To analyze the data collected with the USGS sensor, numuric modeling will be performed to determine the dielectric permittivity from the measurements. Details of the modeling technique are found in Reference 2. The equation that is the basis of this modeling is

$k^{2}=-i \sigma \omega \mu+\omega^{2} \mu \epsilon$.

where

$\omega=$ radian frequency

$\epsilon=$ dielectric permittivity (Farads/meter)

$\sigma=$ conductivity (Scimens/meter)

$\mu=$ magnetic permeability (Henries/meter).

All measurements will be converted 10 resistivity and relative diclectric permiltivity. The equation relating resistivity (ohm-meters) lo conductivity is

$\rho=1 / \sigma$.

The equation for relative dielectric permillivily $K$ is

$K=\epsilon_{i} \epsilon_{0}$

where

$\epsilon_{0}=$ frec-space permittivity of $8.854 \mathrm{pF} / \mathrm{m}$.

The data will then be compared to the known diclectric permittivity ol the models to verily the result. Data validation will be pertorm d by the kest kader and USGS participants. The lest leader is responsible for the datta validation.

\subsection{Contingency Plan}

If a discrepancy arises that cannon be resolved, the ditta will be relitien for the allected lest. unless approval is obtained liom the project mantger to delele the specific, allected lest. Instrument or calibration problems that compromise datal quality and cannot be resolved will be brought to the attention of the project manager for resolution. The project manager will decide whether to continue testing under degraded conditions or take: another course of action. 


\section{QUALITY ASSURANCE}

The work performed under this test plan will conlorm to EG\&G Idaho Quality Level B. The applicable Quality Program Plan is QPP.337. This includes requirements that all instruments are properly calibrated before use, all test setups are documented in the laboratory notebook, and all changes to the test procedures are documented and approved.

Quality assurance activities include keeping a daily loghootk of the datta collected. This will be reviewed by a third party. The equipment used will be calibrated with the melhods used by the USGS in the tool development. The TDR will be calibraled by measuring a known signal on a routine basis and recording instrument readings in the logbook. The dalta will be evaluated for reasonableness by the lest leader or designee. Any nonconlormance issues, such as equipment malfunctions or time delays, will be reported to the program manager who has the respensibility to resolve these issues. 


\section{EQUIPMENT AND INSTRUMENTS}

The majority of the equipment and instrumentation used is either owned by the USGS or EG\&G Idaho. The equipment not owned will be leased. 


\section{SUPPLIES, UTILITIES, AND FACILITIES}

The modeling tank facilities and supplies used are locilted at the Federal Center in Denver, Colorado. The need for facility support personnel is not anticipated. 


\section{HEALTH AND SAFETY}

The anticipated activities for the project are considered renutine with no health or salcly dangers envisioned. Accordingly, hazardous materials such as llammable liquids or carcinogens will not be used, so there are no health or salety issues involved with hazardous matcrials. All silety procedures in place at the modeling facility of the USGS will be followed. The EGeG ldaho Waste Technology Development Department Sell-Assessment Surveillance Report and walk-through checklist will be used to determine if there are any unresolved salety issues at the modeling fincility at the Federal Center in Denver. The Sell-Assessment Surveillance Report and checklist are provided in Appendix $A$. 


\section{RESIDUALS MANAGEMENT}

The residuals are primarily sand, clay, water, and houschold products such as cooking oil. Remaining sand and clay will be retained for luture use. All other residuals will be environmentally safe and disposed of using the existing disposial systems at the Federal Center in Denver. 


\section{REFERENCES}

1. N. E. Josten, "Diglace Characterization." Túchnical Task Plan. TTP ID1321(1)3, 1992.

2. D. C. Stewart, W. L. Anderson, T. P. Grover, and V. F. Labson. "Delection of Shallow Subsurface Layers Using High-Frequency Electromagnetic Sounding in the $3(x) \mathrm{kH} /$ (o) 30 Mhe Range," Geophysics, 1993.

3. American Society for Testing and Materials, "Standard Mechod for Field Meatsurements of Soil Resistivity Using the Four-Electrode Method," Annual Bonk of ASTM Standirds, ASTM o $57-58,1985$.

4. T. P. Grover and D. C. Stewart. Shom Wave Loop)-Loop Sotunder; United States Department of the Interior Geolegical Stoney: Open-File Report 9(1-318. 1990. 
Appendix A

Self-Assessment Surveillance Report and Walk-Through Checklist 
A-2

-

- 


\section{Appendix A}

\section{Self-Assessment Surveillance Report and Walk-Through Checklist}

Date:

We need to walk-through the lacilities where we are sponsoring work. It is required that we visit the facilities at which we sponsor work each quarter with the following in mind:

1. Is the appropriate safety equipment available (i.e.. Is there is a rack for safety glasses and does it have glasses in it! Are there signs indicalting that rubher gloves should be used and are gloves available? Are there lire extinquishers, are exils marked, and do alarms look in good shape.")

2. Does the equipment seem lo he in geod shape? Ale there calibration stickers on the equipment and are they current?

3. Is the housckecping within reason lor the work heing conducted?

4. Do electrical items losk to be in gend repair?!

5. Do the individuals working understand whall we wilnt need and do we understand what they are going le provide us (deliverables)!

6. Are there any operalting procedures being used and are loghooks updated regularly?

7. Are hazardous materialsiequipment marked and handled properly?

8. Il you were paying lor this work out ol your own pockel. would you be happy with what you have scen'?

9. Is there a need for or do incy have liceace protection:!

10. Has the salely of horisting and rigging been addressed now, or is it planned?

This is not an inclusive list nor does every item on the list need an be checked: it is strictly provided as a helplul (o) when looking all your arcils. 


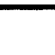

A- 4 
CTS No.

Performer(s)

Cate of Assessment

Facility(s)

Source Identification

Document Reference

Finding Title

Finding No.
Org Assessed

Assessment Target

\section{Compliance Code}

OSHA Code, etc.

Finding Description (Detailed description of Compliance Deficiency)

Current Status (\% Complete)

Corrected on the spot?

Remarks/Recommendations/Positive Observations

Responsible Mgr.

Category

Due Date

Actionee

Corrective Action Description
Org. Priority Level

Funding Source
Cognizant ID Root Cause Code Funding Amt (\$)

Approval

Completion Date

Verified 
A description of each finding category is as follows:

Category 1 - Addresses a situation for which an imminent danger exists to human health or the environment. Requires imediate attention.

Category 11 - Addresses a significant risk or substantial deviation from a DOE Order, code, standard. or regulation: violation of a law (State, Federal, Local), written agreement, or permit condition. The situation does not present a clear and present danger to human health or the environment.

Category 111 - Addresses a deviation from DOE Order, code, standard, or regulation, or addresses a need for an improvement in the margin of safety. Non-application of a requirement described as Best Management Practice (BMP) is also included in this category.

NOTE: All findings that are categorized as Category I and 11 shall have a root cause analys is performed. Findings that are Categorized as a Ill shall have a root cause analysis performed if deemed necessary by the responsible manager. Root cause analys is shall be performed per EG\&G Company Procedure CP-1.6.

A description of priority levels is as follows:

Priority 1 - to be corrected within the next five (5) working days

Priority 2 - to be corrected within the next thirty (30) working days

Priority 3 - to be corrected as soon as practicable with consideration given to budget and schedule

OSHA CODES

1. Walking/working surfaces

2. Means of egress

3. Occupational health and environmental control

4. Mizardous materials

5. Personal protection equipment

6 . General environmental controls

7. Medical and first aid

8. Fire protection

9. Compressed gas and compressed a ir equipment.

10. Materials handling and storage

11. Machinery and hachine guarding

12. Kand and portable power tools

1:. Welding, cutting, and brazing

14 . Electrical

15. Powered platforms, manlifts and vehicle mounted work plateforms.

16. Special industries

17. Ladders and scoffolding

18. Excavations

19. Demolition

20. Cranes, derricks, hoists, elevators, and conveyors

2:. Miscellaneous
Root Cause Codes

1A. Defective or falled part

1B. Defective or falled material

1C. Defective weid, braze, or soldered joint

10. Error by manufacturer in shipping or marking

IE. Electrical or instrument noise

IF. Contamination

2A. Defective or inadequate procedure

2B. Lack of procedure

3A. Inadequate work environment

3B. Inattention to detail

3C. Violation of requirement or procedure

30. Verbal comunication problem

$3 E$. Other human error

$4 A$. Inadequate man-machine interface

4B. Inadequate or defective design

$4 C$. Error in equipment or material selectiori

4D. Orawing, specification or data errors

5A. No training provided

5B. Insufficient practice or hands-on experience

5C. Inadequate content

50. Insufficient refresher training

5E. Inadequate presentation or materials

$6 \mathrm{~A}$. Inadequate administrative controls

68. Work organization/planning deficiency

6C. Inadequate supervision

60. Improper resource a llocation

6E. Policy not adequately defined, disseminated or enforced

$6 \mathrm{~F}$. Other managernent problems

$7 A$. Weather or ambient condition

7B. Power failure or transient

7C. External fire or explosion

7D. Theft, tampering, sabotage, vandalism 

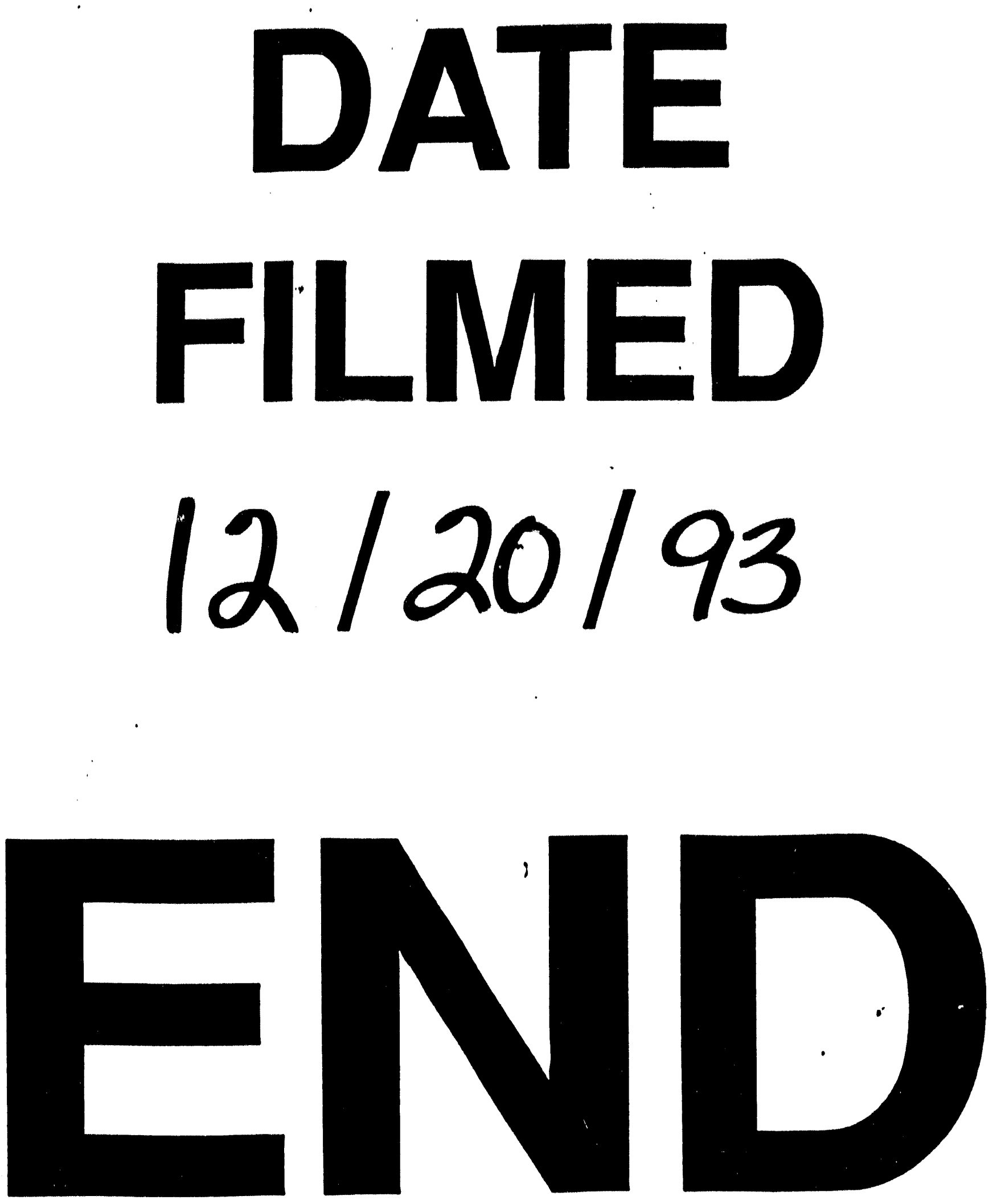
